\title{
A multiple electrode cochlear implant
}

\author{
By G. M. Clark, Y. C. Tong, R. Black, I. C. Forster, \\ J. F. Patrick and D. J. Dewhurst (Melbourne)
}

\section{Introduction}

Ir is generally agreed that if a cochlear implant hearing prosthesis is to enable a patient to understand speech, it must be a multiple-electrode system. In addition, stimulation of the auditory nervous system should approximate the patterns of neural excitation occurring in people with normal hearing, and this is especially important when a patient has previously experienced hearing. For this reason the correct application of electrophysiological principles to the design of a hearing prosthesis is desirable, and is discussed in this paper with special reference to a device developed in the Departments of Otolaryngology and Electrical Engineering at the University of Melbourne (UMDOLEE).

\section{Electrode physicochemistry}

When an electrode is placed in an electrolyte solution, for example, the perilymph, electrical charges become distributed at the electrodeelectrolyte interface and in the neighbouring solution, so that an electrical potential is developed and the electrode is said to be polarized. When an electrical current is made to flow across this electrode it will result in an alteration in this charge distribution and hence the impedance to current flow. As the impedance varies with the size of the current, a constant current stimulator is required to produce a known current.

With electrical stimulation it is preferable that current be passed as a result of double-layer charging at the electrode-electrolyte interface. Otherwise electrolysis will occur with the production of toxic substances. Electrolysis can be avoided if a biphasic stimulus pulse is used so that the double-layer capacitance can be alternately charged and discharged.

As electrical stimulation can lead to the production of toxic materials and the loss of metal from the stimulating electrode (Brummer and Turner, I975), with long term stimulation these toxic materials could build up in the perilymph and lead to the degeneration of auditory nerve fibres. The toxic products produced and the degree of metal loss will depend on the type of metal used, and other factors such as current density and wave shape. Furthermore, the so-called 'noble metals' like platinum are not immune from these processes and careful consideration must be given to minimizing the production of toxic products and metal loss in any metal electrode used in a cochlear implant. 


\section{G. M. Clark et al.}

When a platinum electrode is placed in a solution with the composition of perilymph, the toxic products produced and the degree of metal loss, depend on whether the electrode is positive or negative with respect to ground. If it is positive, there will be an increase in the adsorption of monatomic oxygen (Greatbatch et al., 1969), and this will be released as a gas. Furthermore, chlorine and hypochlorite ions will be formed by oxidation and would be toxic to nerve fibres if produced in quantities that could not be buffered or removed by the perilymph. Studies also show (Brummer and Turner, 1975) that with higher current densities platinum ions will pass into solution, and this will lead to metal loss. Furthermore, when the electrode is negative with respect to ground it will attract hydrogen ions, which will be adsorbed and released as hydrogen.

Studies by Brummer and Turner (1975) have demonstrated that $\mathrm{pH}$ changes and metal dissolution are least when the first part of the biphasic wave is negative (phase lag) with respect to ground rather than positive (phase lead), as illustrated in Fig. Ib, a. This study was carried out using low current densities and platinum black electrodes. It has been demonstrated (Schwan, I963), however, that platinum black electrodes can lose part of their platinum during mechanical insertion, and deteriorate in biological fluids, probably due to the entry of protein molecules into the porous surface. For this reason we consider that smooth platinum rather than platinum black electrodes should be used in cochlear implants, and a study by Black (I977) has confirmed that with these electrodes the loss of platinum is also less when the biphasic wave has a phase lag rather than a phase lead. Consequently, the biphasic waveform selected for the UMDOLEE receiving and stimulating device (Forster and Patrick, 1977) has the phase lag configuration.

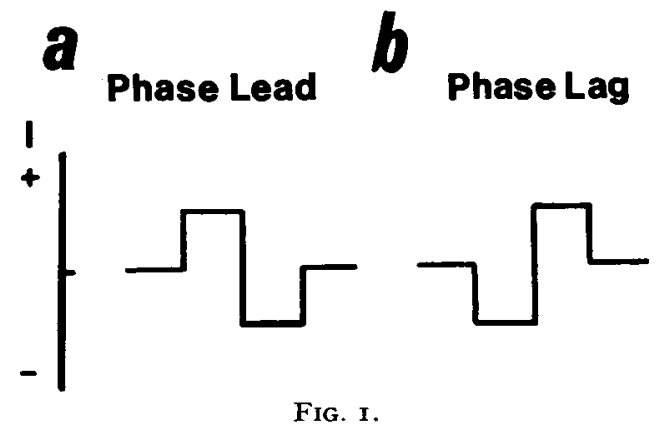

A diagram of biphasic current waveforms. a, phase lead; b, phase lag.

As high current densities can cause metal loss, a study has been undertaken by Black (1977), using a sensitive spectro-photometric technique for detecting platinum, to determine more precisely how the maximum current density used by the UMDOLEE prosthesis is likely to affect the 


\section{A multiple electrode cochlear implant}

life of the multiple-stranded wire bundle or the sputtered platinum ribbon array used with this device. This study showed the average dissolution of platinum at a current density of $2 \mathrm{~mA} / \mathrm{sq} \mathrm{mm}$, to be $20 \mathrm{ng} /$ day at a pulse repetition rate of $\mathbf{I ~} \mathrm{kHz}$ with the phase lag configuration. Furthermore, in order to achieve a maximum current density no greater than $2 \mathrm{~mA} / \mathrm{sq} \mathrm{mm}$ the UMDOLEE cochlear implant has been designed so that with the multiple-stranded wire bundle, the surface area of the electrode is $0.5 \mathrm{sq}$ $\mathrm{mm}$ and the distance between electrode centres is $\mathrm{x} \cdot 2 \mathrm{~mm}$. On the other hand, with the sputtered-platinum ribbon array the surface area of the electrode is $0.5 \mathrm{sq} \mathrm{mm}$ and the distance between the electrode centres is I. $65 \mathrm{~mm}$ (Clark and Hallworth, I976; Hallworth, I976). When used continuously with a maximum current density for an average of Io hours/day, the multiple-stranded wire would have a life of about 90 years before $50 \%$ of the metal would be lost, and in the case of the sputtered-ribbon array it would be about ro years.

\section{Neural excitability}

When neural tissue is stimulated it is the current flowing through the tissue rather than the voltage across the electrodes which is important in generating action potentials, and for this reason it is important to specify the stimulus current rather than the voltage. It is also another reason why a constant current stimulator is required, and the UMDOLEE receiver-stimulator unit permits a range of stimulation from $0 \mathrm{~mA}$ to $\mathrm{I} \mathrm{mA}$ (Forster and Patrick, I977).

The width of the stimulus pulse is also significant in electrical stimulation of nerve fibres. A strength-duration curve (Fig. 2a) carried out on a frog sciatic nerve (Blair, I935) shows that the tissue has a chronaxie of $0.36 \mathrm{msec}$, and this indicates that a greater current is required to reach threshold for stimulus pulses with durations less than $0 \cdot 36 \mathrm{msec}$. This relation between current and duration reflects the amount of current flowing per unit of time or number of Coulombs, which is the parameter most responsible for initiating a nerve action potential.

Studies on electrical stimulation of auditory nerve fibres by Clark (I969) have shown that for pulses with widths of $0 \cdot 0 \mathrm{I}-0 \cdot \mathrm{I} \mathrm{msec}$, stimulus threshold levels varied from $0 \cdot 003-01 \mathrm{~mA}$. Another study by Clark $e$ t al., (I972) showed that there was no difference in behavioural thresholds for electrical stimulation of the cochlea with pulse widths of $0 \cdot I$ and $I \cdot 0$ msec. More recently a study by Black and Clark (1977) has determined the strength-duration curve for electrical stimulation of the auditory nerve fibres, and this is shown in Fig. $2 \mathrm{~b}$. This was obtained by recording the auditory nerve field potential in response to electrical stimulation of the terminal auditory nerve fibres between an active electrode in the basal turn of the cochlea and a ground on the neck. The chronaxie was $0 \cdot 18$ msec which is half that of the frog sciatic nerve. This means that a greater 


\section{G. M. Clark et al.}

current is required to reach threshold for stimulus pulses with durations less than $0 \cdot 18 \mathrm{msec}$. From these findings on neural tissue it has been considered appropriate to use biphasic current pulses with a width of $0 \cdot 18$ msec per phase.

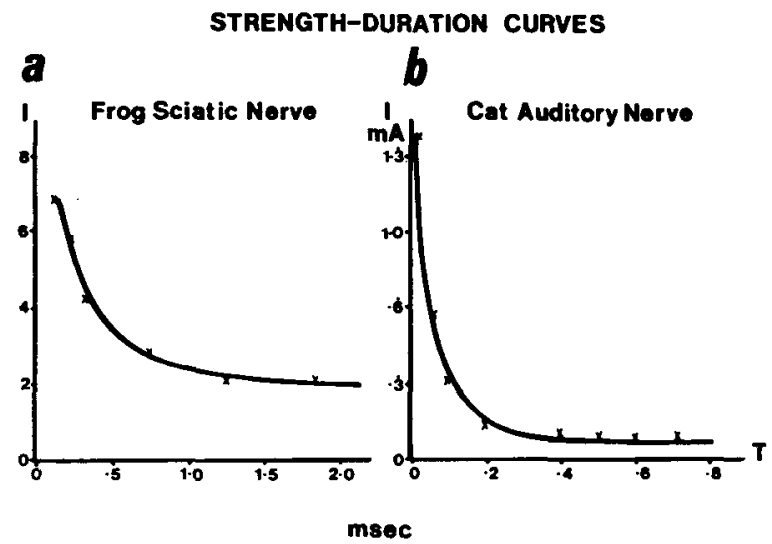

FIG. 2.

Strength-duration curves. a, frog sciatic nerve (drawn from Blair, 1935); b, cat auditory nerve (Black and Clark, r977).

As acute and behavioural studies on cats (Clark et al., I972, Williams et al., 1976) and studies on humans (Simmons et al., I965) have shown that rates up to 800 pulses per second can be discriminated, it was also felt that a biphasic pulse width of $0.18 \mathrm{msec}$ phase would allow this range to be covered with an adequate inter-stimulus recovery period.

\section{Frequency coding}

There have been two main theories of frequency coding. The first or volley theory states that frequency perception depends on the brain cells firing in phase with consecutive cycles of a sinusoidal sound stimulus. The second or place theory states that frequency perception depends on the site of stimulation of the auditory brain cells. It was thought that the volley theory was only relevant to the coding of low frequency sound, as higher rates of stimulation did not produce an appropriate increase in the rate of neural firing due to the refractory period of the nerve. The place theory was thought to explain the coding of higher frequencies. Furthermore, there have been other theories which have been modifications of these. For example, Allanson and Whitfield (1956) and Whitfield (I967) have postulated that frequency is signalled by the relative position of the fibres at the edge of a population of neurones, and Licklider (I959) has developed a model showing that a time-to-place conversion could occur in the central nervous system. 


\section{A multiple electrode cochlear implant}

Further research has, however, revealed that the volley theory could explain coding at higher frequencies than previously thought as histograms showed that although one particular nerve fibre could not fire in phase with every consecutive cycle of stimulation, at high rates of stimulation it could fire at a particular phase every second, third and fourth cycle (Rose et al., I967). The net result of this was that in a population of nerve fibres some were always firing at a constant phase on every sound wave.

Although this work is interesting and suggests that the volley theory may be quite significant in frequency coding, there are increasing data which indicate that the place theory is of greater importance, and this evidence has been summarized by Evans ( $1975 \mathrm{a}, \mathrm{b}$ ). In particular, psychacoustic studies by Wilson $(1967,1970)$ have shown that white noise, which has been altered to produce stimuli with multiple-component spectra, can be used to excite various localized regions of the cochlea, corresponding to the peaks of the spectral waveform, and that the pitch sensations produced, varied depending on the site of stimulation of the cochlea, and the distance between the stimulating peaks. As the white noise stimulus has no effect on a volley basis, this is good evidence for the place theory. Furthermore, these studies showed the frequency-resolving capacity of the cochlea was consistent with its functioning like a series of linear band-pass filters.

As these and other studies have shown the importance of the place theory in pitch perception, the receiving-stimulating device has been designed to stimulate groups of auditory nerve fibres at a number of different sites. It is also considered that the area of stimulation should be restricted to the critical band as this is the frequency band which is consistent with the frequency-resolving capacity of human subjects as measured with comb-filtered noise (Wilson and Evans, 197I). As each critical band is equivalent to a distance of approximately $\mathbf{I} \cdot 2 \mathrm{~mm}$ along the basilar membrane, it has been the aim, in the case of UMDOLEE device, to restrict the stimulus from each electrode to this area.

The number of sites to be stimulated, and consequently the number of electrodes to be used must also be considered. On the basis of the number of critical bands in the speech frequency region, this would mean I5 electrodes. Further evidence for the use of a minimum of ro electrodes can be obtained from channel vocoder studies (Evans, I975b). Consequently, the UMDOLEE device has the capacity to stimulate ro electrodes, and can be enlarged to accommodate I5.

With electrical stimulation of the auditory nerve fibres in the cochlea it has been shown that there are likely to be difficulties in achieving a restriction of electrical current flow to a group of nerve fibres in the critical band. Studies on the electroanatomy of the cochlea by Békésy (r95I), Misrahy et al. (r958), Johnstone and Johnstone (1966), have shown that the scala tympani is a low resistance electrical pathway, and this will in- 


\section{G. M. Clark et al.}

crease the spread of the electrical field along the cochlea. These electroanatomical findings have been confirmed with physiological studies by Kiang and Moxon (I972), and Merzenich et al. (I973).

The spread of the electrical field along the scala tympani is expressed quantitatively as the length constant. This is the distance along the scala over which the electrical voltage is reduced by 1/e or approximately $9 \mathrm{~dB}$. Alternatively, it may be expressed as the voltage drop in $\mathrm{dB} / \mathrm{mm}$. Békésy (r95I) found the voltage drop to be $6 \mathrm{~dB} / \mathrm{mm}$ throughout the cochlea of the guinea pig. The length constant as determined by Misrahy et al. (I958) was $0.2 \mathrm{~mm}$ in the apical and $2 \mathrm{~mm}$ in the basal turn, and Johnstone and Johnstone (I966) found it to be $2 \mathrm{~mm}$ in the basal turn.

Special measures may be taken to reduce the longitudinal spread of the current by filling the scala tympani with material with a high resistance, as is performed in the basal turn by Michelson et al. (1973). This is more difficult to do in the apical and middle turns, but nevertheless in any turn it is not completely satisfactory as it can result in damage to the basilar membrane and spiral lamina and consequent loss of residual auditory nerve fibres. Thus, it is necessary to consider other ways of restricting the current flow, and sharpening the electrical stimulus field.

One possible way of producing a sharpening of the stimulus field has been postulated by Thornton (personal communication). Using a computer model he showed that if the phase relations of the pulses in the electrodes on either side of the one being stimulated are varied (Fig. 3)

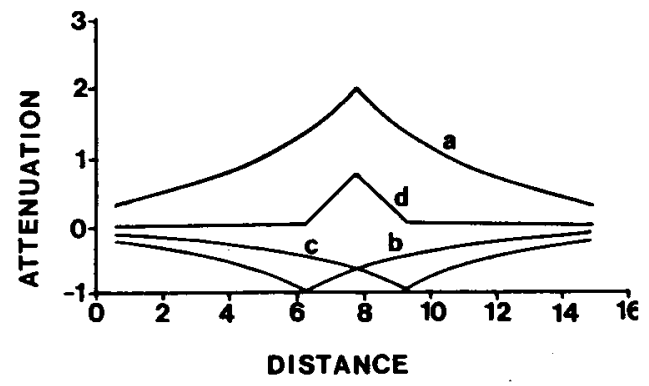

FIG. 3 .

A plot of the sharpening of the electrical field according to a model of Thornton (personal communication). a, the electrical field with a $2 \mathrm{~mA}$ pulse to central electrode; $b$, c, the electrical field with a, I mA pulse to neighbouring electrodes; d, the resultant electrical field.

this could result in sharpening. This has been confirmed with a physiological study by Black and Clark (I977), which has shown neural sharpening as a result of these electrical stimuli. Furthermore, a behavioural study by Minas (1973) demonstrated that there was a difference in a cat's response to simultaneous electrical stimulation of neighbouring electrodes, depending on whether they were in phase or out of phase with each other. 


\section{A multiple electrode cochlear implant}

Consequently, the capacity to present electrical stimuli to neighbouring electrodes $180^{\circ}$ out of phase and sharpen the electrical field is planned for the UMDOLEE receiving and stimulating device. This will allow the phases of the pulses in the electrodes on either side of a central one to be varied.

An alternative way of restricting electrical stimulation to a localized group of nerve fibres has been discussed by Evans (I975b). This is a consequence of the electroanatomy of the cochlea and the limited dynamic range of auditory nerve fibres to electrical stimulation. With an acoustic stimulus the fibres will respond from threshold to maximal rate of firing over a range of $20-50 \mathrm{~dB}$ (Evans, I975a). On the other hand, with electrical stimulation the dynamic range is only $6 \mathrm{~dB}$ (Kiang and Moxon, I972). Furthermore, when stimulating the central electrode just below maximal levels the $6 \mathrm{~dB} / \mathrm{mm}$ drop due to the length constant will result in nerve fibres $\mathrm{I} \mathrm{mm}$ away receiving a stimulus $6 \mathrm{~dB}$ less than the central one. As the dynamic range of the fibres to electrical stimulation is $6 \mathrm{~dB}$, the fibres at a distance of $\mathrm{I} \mathrm{mm}$ will receive a stimulus that is just below threshold. In order to achieve restriction of current flow on this basis it is necessary to be able to use the receiving and stimulating device to adjust the threshold level and operating range for each electrode independently, and this facility has been incorporated into the UMDOLEE prosthesis (Forster and Patrick, 1977).

The theories of frequency coding discussed above do not explain all the facts; for example, subjects can perceive pitch at high intensities and at levels where experimental studies have shown that the auditory nerve fibres are saturated with respect to their firing rate (Evans, r975b). One possible explanation is that when saturated, the fine structure of neural firing for a single nerve may also be important. This is supported by physiological studies which have shown that saturated fibres can carry information in their pattern of discharge (de Boer, r969; Ruggero, r973; Evans, I975b).

In order to vary the pattern of electrical stimulation for individual and groups of electrodes, the UMDOLEE receiving and stimulating device has been designed so that the timing of the stimulus pulse is independently controlled for each electrode. The timing sequence for a single channel is shown in Fig. 4. Stimulus control information is received for that channel at what is described as the frame rate, which defines the maximum average rate of stimulus presentation.

In each frame there are eight reference times, one of which is specified by the stimulus control information, as the time at which stimulation commences. In the example in Fig. 4 the stimulus in frame $n$ starts at reference time 7 , and will extend into frame $n+I$. In the frame $n+I$ the first available reference time is 3 , and should stimulus control data specify an earlier stimulus time in frame $n+x$ no stimulus will occur in that frame. 


\section{G. M. Clark et al.}

The amplitude of the current pulse may be set at any one of $I 6$ levels (Forster and Patrick, 1977).

The overall timing sequence for the 15 electrodes can be seen in Fig. 5, which shows that the information for the current amplitude and relative time of stimulation within each frame is stored within time bins for each electrode. The independent control of stimulation from each electrode allows a wider range of stimulus patterns than if the electrodes had to be stimulated sequentially.

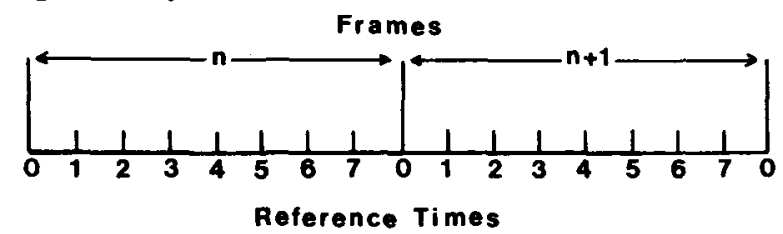

Stimuli

FIG. 4 .

A diagram of the timing sequence for a single channel of stimulation used by the receiving and stimulating component of the UMDOLEE multiple-electrode hearing prosthesis.

TIMING SEQUENCE

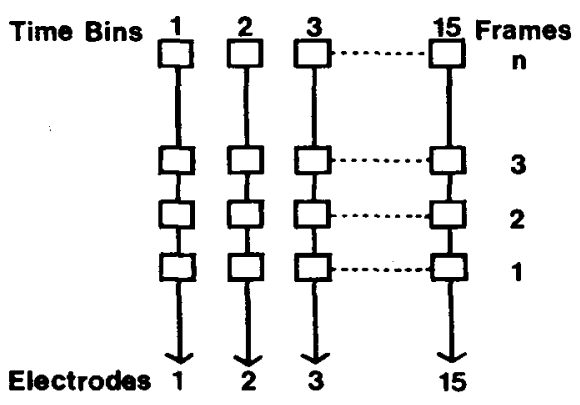

TIME BINS

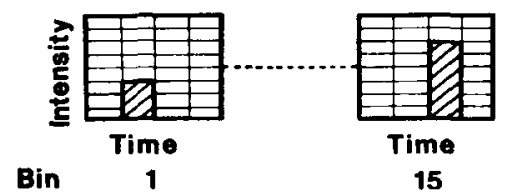

FIG. 5 .

A diagram of the overall timing sequence and structure of the time bins used by the receiving and stimulating component of the UMDOLEE multiple-electrode hearing prosthesis.

\section{Intensity coding}

It was thought that intensity could be coded by a change in the overall rate of nerve firing and variations in the number of nerve fibres being stimulated. There is, however, physiological and psychacoustic evidence 


\section{A multiple electrode cochlear implant}

to indicate that these theories need to be modified. Firstly, with regard to rate of firing, physiological studies have shown that individual cochlear fibres have a restricted dynamic range, and can only code intensity differences over a range of about $20-50 \mathrm{~dB}$. Furthermore, the wide dynamic range of the ear cannot be covered by a series of fibres with different thresholds, as Evans (I975a) has shown that the thresholds for auditory nerve fibres are similar at each frequency, providing some form of trauma does not damage the 'neural filter', and cause a pathological increase in the thresholds of some fibres.

Secondly, with regard to the number of nerve fibres excited, psychoacoustic studies by Viemeister (1974) have shown that subjects could perceive the whole I20 $\mathrm{dB}$ dynamic range even though the effects of intensity on the spread of the basilar membrane travelling wave were prevented by band-stop noise. In this study the band-stop noise masked the neighbouring areas of the cochlea, and increases in intensity could not excite a greater population of auditory nerve fibres.

In view of the findings described above it would appear that the coding of intensity is not carried out simply on the basis of the mean rate of nerve firing or the population of nerves excited. Further studies by Evans and Palmer (I975) have been undertaken to investigate possible mechanisms involved. This work has shown that single auditory nerve fibres have a restricted dynamic range, but this is not the case with the neurons in the dorsal cochlear nucleus which have a roo $\mathrm{dB}$ range. This work suggests that there is an interaction between the inputs to the auditory nerve fibres at the cochlear nucleus level, and that the extended range in intensity is possible through excitation-inhibition interaction or variations in the pattern of firing within single nerve fibres.

This means that as far as a cochlear implant hearing prosthesis is concerned, it should have the flexibility of varying the pattern of discharges independently to the different electrodes. This has been incorporated into the design of the UMDOLEE receiving and stimulating device and the timing cycle that enables the pattern of stimulation to be varied to individual or groups of electrodes is illustrated in Fig. 4.

\section{Summary}

The University of Melbourne Departments of Otolaryngology and Electrical Engineering (UMDOLEE) receiving and stimulating component of a multiple-electrode cochlear implant hearing prosthesis produces constant current stimulation. It has a stimulating pulse shape that minimizes the production of toxic substances and loss of metal from the electrodes, and this is achieved with a biphasic rectangular waveform where the first phase is negative with respect to ground. The duration of each stimulus phase is $180 \mathrm{msec}$, which is long enough to allow low levels of current stimulation, and short enough to permit rates of rooo pulses/ 


\section{G. M. Clark et al.}

second to be achieved. In order to be consistent with our present under: standing of the perception of pitch, the device permits the independent stimulation of a number of electrodes. Furthermore, to electrically isolate the stimulus to small areas, there is the capacity to vary the current and set the threshold independently at individual electrodes. The phase and amplitude of the pulses to neighbouring electrodes will also be varied to assist in localizing the current flow. The pattern of stimulation to individual or groups of electrodes can also be altered to enable studies to be carried out to determine ways of conveying frequency and intensity information over a more normal dynamic range.

\section{Acknowledgments}

We would like to acknowledge the financial assistance provided by the National Health and Medical Research Council of Australia and the Channel O Nerve Deafness Appeal. Telecom Research Australia have assisted greatly with technical assistance.

We would also like to thank Mr. R. J. Walkerden for technical assistance, Mr. L. Cole for the photographic work and Miss J. Maher for the typing.

\section{REFERENCES}

Allanson, J. T. and Whitfield, I. C. (1956) The cochlear nucleus and its relation to theories of hearing. In 3rd London Symposium on Information Theory, 269, ed. C. Cherry, Butterworth, London.

BÉkesy, G. Von, (195I) Journal of the Acoustical Society of America 23, I8.

BLACK, R. (I977) (Submitted for publication).

Black, R. and Clark, G. M. (I977) Proceedings of the Australian Physiological Society, 8, 137 .

BLAIR, H. A. (I935) Journal of General Physiology 18, 755.

BoEr, E. De (1969) Proceedings of Koninklijke Nederlandse Akademie van Wetenschappen 72, 129 .

Brummer, S. B. and Turner, M. (1975) The Eighth and Ninth Quarterly Report: Implantable Electrodes, National Institute of Health, Bethesda, Maryland.

Clark, G. M. (1969) Experimental Neurology 24, 124.

Clark, G. M. and Hallworth, R. J. (1976) Journal of Laryngology and Otology 90, 623 .

Clark, G. M., Nathar, J. M., Kranz, H. G. and Maritz, J. S. (1972) Experimental Neurology 36, $35^{\circ}$.

Evans, E. F. (1975a) Cochlear nerve and nucleus, In: Handbook of Sensory Physiology, Vol. V/2., eds. Keidel, W. D. and Neff, W. D., Springer, Berlin.

Evans, E. F. (1975b) Experimental (physiological and otherwise) considerations concerning artificial stimulation of the auditory system. Proceedings of the Second British Conference on Audiology.

Evans, E. F. and Palmer, A. R. (I975) Journal of Physiology 252, 6oP.

Forster, I. C. and Patrick, J. F. (I977) (Submitted for publication).

Greatbatch, W., Piersmal, B., Shannon, F. D. and Calhoon, S. W. (ig69) Annals of the New York Academy of Science 167, 722.

Hallworth, R. J. (I976) M.Eng. Thesis, University of Melbourne.

Johnstone, B. M. and Johnstone, J. R. (I966) Journal of the Acoustical Society of America 40, I398. 


\section{A multiple electrode cochlear implant}

Kiang, N. Y. S. and Moxon, E. C. (1972) Annals of Otology 81, 7I4.

Licklider, J. C. R. (I959) Three auditory theories, In: Psychology: A study of a Science, Ed. S. Koch, McGraw-Hill, New York.

Merzenich, M. M., Michelson, R. P., Pettit, C. R., Schindler, R. A. and Reid, M. (I973) Annals of Otology 82, 486 .

Michelson, R. P., Merzenich, M. M., Pettit, C. R. and Schindler, R. A. (I973) Laryngoscope 83, I I I6.

Minas, H. (1973) B. Med. Sc. Thesis, University of Melbourne.

Misrahy, G. A., Hildreth, K. M., Shinabarger, E. W. and Gammon, W. J. (I958) American Journal of Physiology 194, 396.

Rose, J. E., Brugge, J. F., Anderson, D. J. and Hind, J. F. (1967) Journal of Neurophysiology 30,769.

RugGero, M. A. (1973) Journal of Neurophysiology 36, 569.

Schwan, H. P. (1963) Determination of biological impedances, In: Physical Techniques in Biological Research, ed. W. L. Nastuk, Academic Press, New York.

Simmons, F. B., Epley, J. M., Lummis, R. C., Guttman, N., Frishkopf, L. S., HARMON, L. D. and ZwICKER, E. (1965) Science 148, 104.

Thornton, A. R. D. (Personal communication).

Viemeister, N. F. (1974) Journal of the Acoustical Society of America 56, 1594.

Whitfield, I. C. (1967) Nature 213, 756.

Williams, A. J., Clark, G. M. and Stanley, G. V. (1976) Physiological Psychology $4,23$.

Wilson, J. P. (1967) Psychoacoustics of obstacle detection using ambient or selfgenerated noise, In: Les Systèmes Sonars Animaux, 89, ed. R. G. Busnel, LouisJean, Gap, Haut-Alpes, France.

Wilson, J. P. (I970) An auditory after-image, In: Frequency Analysis and Periodicity Detection in Hearing, 303. Eds. R. Plomp and G. F. Smornenburg, Sijthoff, Leiden.

Wilson, J. P. and Evans, E. F. (1971) Proceedings of the Seventh International Congress on Acoustics, 397.

Dept of Otolaryngology,

The Royal Victorian Eye and Ear Hospital,

32 Gisbourne Street,

East Melbourne 3002,

Victoria, Australia. 



\section{University Library}

\section{- M M N E R VA A gateway to Melbourne's research publications}

Minerva Access is the Institutional Repository of The University of Melbourne

Author/s:

Clark, Graeme M.;Tong, Y. C.;Black, R.;Forster, I. C.;Patrick, J. F.;Dewhurst, D. J.

Title:

A multiple electrode cochlear implant

Date:

1977

Citation:

Clark, G. M., Tong, Y. C., Black, R., Forster, I. C., Patrick, J. F., \& Dewhurst, D. J. (1977). A multiple electrode cochlear implant. Journal of Laryngology and Otology, 91(11), 935-945.

Persistent Link:

http://hdl.handle.net/11343/27160 